\title{
Özgün araştırma makalesi \\ Preform ark tellerinin dental arklar üzerine etkilerinin 3D model analizi ile değerlendirilmesi
}

\author{
Gamze Metin Gürsoy iD, * Sevil Akkaya iD \\ Ortodonti Anabilim Dalı, Diş Hekimliği Fakültesi, \\ Gazi Üniversitesi, Ankara, Türkiye
}

\section{Özet}

AmAÇ: Çalışmanın amacı, sabit ortodontik tedavilerde kullanılan prefabrik ark tellerinin maksiller ve mandibular çene dental ark formu üzerine etkilerinin 3-boyutlu (3D) olarak değerlendirilmesidir.

Gereç ve Yöntem: Çalışmaya Gazi Üniversitesi Diş Hekimliği Fakültesi Ortodonti Anabilim Dalında tedavi görmüş maksilla ve mandibulada yaklaşık $3 \mathrm{~mm}$ olmak üzere $\mathrm{mi}-$ nimal çapraşıklığa sahip olan 46 bireyin tedavi başı (T0) ve tedavi sonu (T1) dental modelleri dahil edildi. Dental alçı modelleri 3Shape R700 3D Scanner ile taranarak STL görüntü dosyaları şeklinde, 3Shape ortho analyzer software programına aktarıldı. 3D görüntüler üzerinde maksilla ve mandibula için inter-kanin, inter-1. premolar, inter-2. premolar, inter-molar mesafeler, kanin derinliği, molar derinliği ölçümleri yapıldı. Maksilla için ayrıca alan hesaplanması tüm dişlerin mukogingival birleşim hattı ile distalde 1. molar dişlerin distal noktaları arasındaki alan için yapıldı. Normallik varsayımının incelenmesinde Kolmogorov-Smirnov testi kullanıldı. Tanımlayıcı istatistikler, ortalama ve standart sapmalar şeklinde sunuldu. Bağımlı iki grubun karşılaştırılmasında eşleştirilmiş t-testi kullanıldı. Anlamlılık düzeyi için sınır 0.05 olarak alındı.

BuLGULAR: Maksillada kanin derinliği, mandibulada ise inter-kanin genişlik haricinde tüm değerlerde tedavi ile anlamlı artışlar görüldü. Maksillada en fazla artış $2.6 \mathrm{~mm}$ ile 1. premolar dişler arasında izlenirken, mandibulada $2.45 \mathrm{~mm}$ ile 2. premolar dişler arasında izlendi $(p<0.001)$. Maksiller alan artışı ise ortalama $81.69 \mathrm{~mm}^{2}$ ile anlamlı bulundu $(p<0.001)$. Molar derinlik artışı hem maksilla hem de mandibula için $0.5 \mathrm{~mm}$ olarak tespit edildi $(p<0.001)$.

Sonuç: Hastaların tedavi başı ark formuna uygun olarak seçilen $\mathrm{Ni}$-Ti seviyeleme arkları hem maksilla hem de mandibulada transversal yönde anlamlı artışlara sebep olmaktadır.

Anahtar Kelimeler: Ortodonti; ortodontik teller; üç-boyutlu görüntü

Makale gönderiliş tarihi: 2 Eylül 2020; Yayına kabul tarihi: 6 Ocak 2021 *iletişim: Dr. Gamze Metin Gürsoy, Gazi Üniversitesi Diş Hekimliği Fakültesi, Ortodonti Anabilim Dalı, 06510, Emek, Ankara, Türkiye;

E-posta: gamze.metin.gursoy@gazi.edu.tr
Kaynak Göstermek İçin: Metin Gürsoy G, Akkaya S. Preform ark tellerinin dental arklar üzerine etkilerinin $3 \mathrm{D}$ model analizi ile değerlendirilmesi. Acta Odontol Turc 2021;38(3):75-80

EdiтöR: Emine Kaygısız, Gazi Üniversitesi, Ankara, Türkiye

YAYIN HAKKI: @ 2021 Metin Gürsoy ve Akkaya. Bu eserin yayın hakkı Creative Commons Attribution License ile ruhsatlandırıımıştır. Sınırsız kullanım, dağıtım ve her türlü ortamda çoğaltım, yazarlar ve kaynağın belirtilmesi kaydıyla serbesttir.

FinANSAL DESTEK: Bulunmamaktadır.

ÇıKAR ÇATıŞMASI: Bulunmamaktadır.

[Abstract in English is at the end of the manuscript]

\section{Giriş}

Ortodontik tedavi planlamalarının ve uygulamalarının temel taşı olan dental arklar, ortodonti alanının en önemli konularından biridir. Fonksiyonel, estetik ve kaIıcı tedavi sonuçlarına ulaşılmasında kişiye özgü doğru ark formunun belirlenmesi ve tedavi başı ark formunun ve boyutlarının korunması özellikle nüks açısından kritik aşamalardan biridir. ${ }^{1,2}$ Dental ark form ve boyutları bireyler arasında kısadan kareye, uzundan konik forma kadar farklılıklar gösterebilmektedir. ${ }^{3}$ Ark formu öncelikle intrauterin hayatta şekillenmeye başlamaktadır. Dişlerin sürme yollarındaki farklılıklar, destekleyici kemik yapıların büyümelerindeki farklılıklar, dişlerin sürmeleri sonrasında zararlı alışkanlıklar veya dengesiz kas basınçları nedeniyle oluşan diş hareketlerinin hepsi ark formu ve büyüklüğü üzerinde etkilidir. ${ }^{4}$ Geçmişten günümüze birçok ark formu belirlenmiş ve klinik kullanıma sunulmuştur. Günümüzde de yaygın olarak standart boyutlara ve özel şekillere sahip olan ark telleri kullanılmaktadır. Hastanın dental ark formunu ve boyutlarını etkileyen başlıca klinik faktörler dental ark perimetresi (meziyodistal genişliklerin toplamı), ark genişliği ve ark derinliğidir. ${ }^{5,6}$ Çalışmalar düzgün sıralanmış dişlerin genellikle kare, oval ve konik formda olduğunu göstermektedir. Bu formlara ilaveten dar, normal ve geniş arklar bireyler arasında farklılıklar yaratmaktadır. ${ }^{7,8}$ Özellikle yüksek elastikiyete sahip preform nikel titanyum (Ni-Ti) alaşımlı ark telleri seviyeleme aşamasında klinisyenler tarafından oldukça tercih edilmektedir. Preform ark formuna sahip olmaları nedeniyle bu ark telleri ile hastanın kendine özel olan ark şekli korunamaya- 
bilmektedir. ${ }^{5} \mathrm{Bu}$ ark tellerinin seviyeleme aşamasındaki başarılı sonuçlarına rağmen ortodontik tedaviler sırasında ark formlarında yapılan büyük değişikliklerin tedavi sonrası nükslerden sorumlu olduğu da bilinmektedir. Farklı formlara sahip nikel titanyum ark tellerinin mandibular kanin dişler arasında ortalama 5.95 mm'lik bir genişleme oluştururken, molar dişler arasında ise oldukça minimal $(0.84 \mathrm{~mm})$ bir genişleme oluşturdukları çalışmalarda gösterilmiştir. ${ }^{5}$ Ark formlarının ve büyüklüklerinin değiştirilmeden yapıldığı bir ortodontik tedavi mümkün müdür ya da bu değişiklikleri yaparken sınırlarımız nedir soruları halen ortodonti alanının en dikkat çekici konuları arasında yer almaktadır.

Daha önceki çalışmalar dental ark değişimlerini 2 boyutlu metotlarla analiz etmişlerdir. Genellikle kullanılan referans noktaları da kesici dişlerin insizal kenarları veya tüberkül tepeleri olarak alınmıştır. İndirekt klinik braket noktaları da çalışmalarda kullanılan bir diğer referans noktasıdır.,9-11 Teknolojinin gelişmesi ile birlikte 3 boyutlu (3D) analizlerin yapılabilir olması araştırmacıların daha gerçekçi ölçümler yapabilmek üzere farklı referans noktaları kullanımlarına olanak sağlamıştır. ${ }^{12,13}$ Çekimli ve çekimsiz sabit ortodontik tedaviler sonucu ark genişliklerinin ve uzunluklarının değiştiği bir çok çaIsşmada gösterilmiştir. ${ }^{14,15} \mathrm{Bu}$ çalışmanın amacı minimal çapraşıklık vakalarında uygulanan sabit ortodontik tedavilerde kullanılan preform ark tellerinin alt ve üst çene dental ark formu üzerine etkilerinin üç boyutlu olarak değerlendirilmesidir.

\section{Gereç Ve Yöntem}

Bu retrospektif çalışma için Gazi Üniversitesi Etik Komisyonu onayı (sayı: 77082166-604.01.02- araştırma kodu: 2018-191) alındıktan sonra Gazi Üniversitesi Diş Hekimliği Fakültesi Ortodonti Anabilim Dalında tedavi görmüş maksilla ve mandibulada $3 \mathrm{~mm}$ 'den daha az çapraşıklığa sahip olan 46 bireyin tedavi başı (T0) ve tedavi sonu (T1) dental modelleri dahil edildi. Bireylerin sınıf I kapanışa sahip olup sabit ortodontik tedavilerinde seviyeleme aşamasında preform $\mathrm{Ni}$-Ti ark tellerinin kullanılmış olması, tedavi protokolü olarak bireysel planlama dahilinde keser protrüzyonu ve/veya interproksimal aşındırma ile yer kazanılmış olmakla birlikte genişletme hedeflenmemiş olması, 0.018 " slot roth tipi braket kullanılarak tedavi edilmiş olmaları, sabit ortodontik tedavi öncesinde veya sırasında herhangi bir genişletme aygıtı veya mekaniği kullanılmamış olması dahil edilme kriterleri olarak belirlendi. Alçı modellerin üç boyutlu taramaları için ve üç boyutlu ölçüm programı olarak 3Shape Ortho System (3Shape A/S, Copenhagen, Danimarka) kullanıldı. Kriterlere uygun 46 bireyin tedavi başı ve tedavi sonu alt ve üst çene alçı dental modelleri 3Shape R700 3D Scanner (3Shape A/S) ile taranarak STL görüntü dosyaları şeklinde 3Shape ortho analyzer software (3Shape A/S) programına aktarıldı. T0 ve T1'de elde edilen üç boyutlu görüntüler üzerinde maksilla ve mandibula için yapılan dental ölçümler aşağıda sıralanmıştır (Şekil 1);

1. İnter-kanin mesafe (13-23; 33-43)

2. Inter-1. premolar mesafe (14-24; 34-44)

3. Inter-2. premolar mesafe (15-25; 35-45)

4. İnter-molar mesafe (16-26; 36-46)

5. Kanin derinliği

6. Molar derinliği

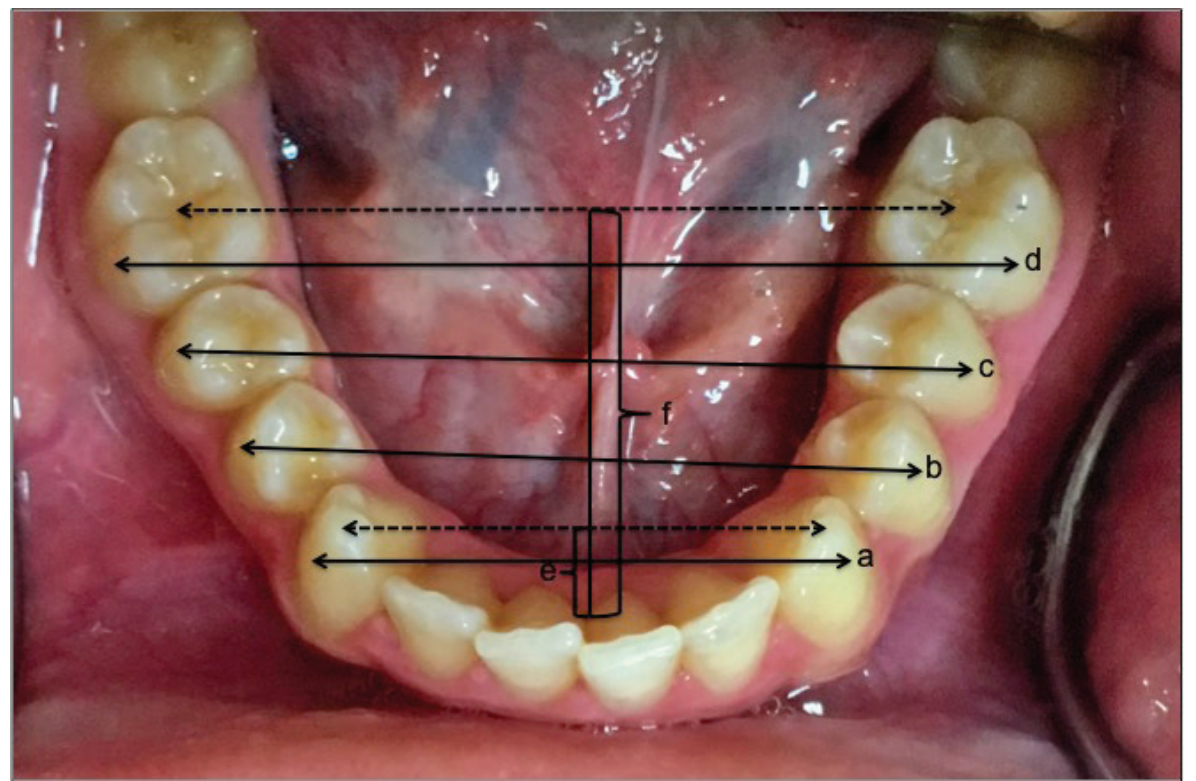

Şekil 1. Referans noktaları dişlerin bukkal yüzeylerinde braketlerin yerleştirilme alanlarının orta noktası olarak 3D görüntü üzerinde belirlenmiştir; (a) interkanin mesafe, (b) inter 1.premolar mesafe, (c) inter 2.premolar mesafe, (d) inter molar mesafe, (e) kanin derinliği en ilerideki kesici dişlerin interproksimal dişeti seviyesi ile kanin dişlerin tüberkül tepeleri arasındaki yatay çizgiye dik uzakık, (f) molar derinlik molar dişlerin santral fossaları arasındaki yatay çizgi ile en ilerideki kesici dişlerin interproksimal dişeti seviyesi arasındaki dik uzaklık 


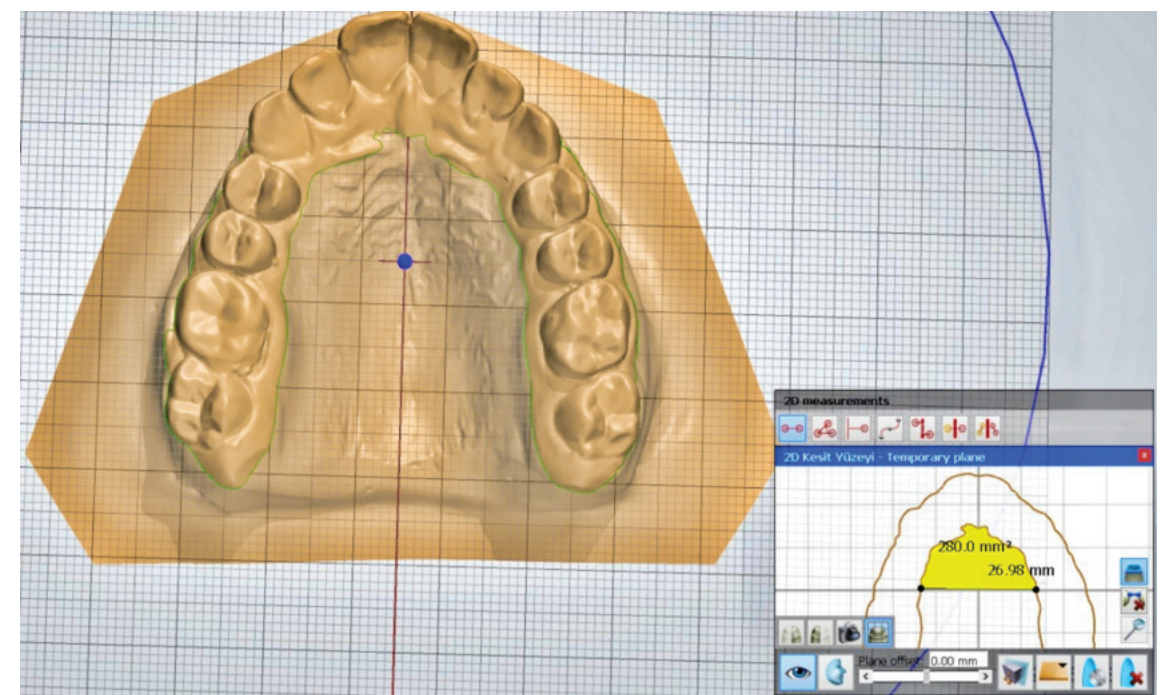

Şekil 2. Maksillada alan ölçümü; tüm dişlerin mukogingival birleşim hattı ile distalde 1. molar dişlerin distal noktaları arasındaki alan için yapıldı.

Dişler arası mesafelerin ölçümünde kullanılan referans noktaları dişlerin bukkal yüzeylerinde braketlerin yerleştirilme alanlarının orta noktası olarak belirlendi. Braket yerleştirme noktalarının belirlenmesinde yine dikey ve yatay yön ölçümleri yapılarak orta noktalar tespit edildi. Kanin derinliği ölçümleri en ilerideki kesici dişlerin interproksimal dişeti seviyesi ile kanin dişlerin tüberkül tepeleri arasında çizilen yatay çizgi arasındaki dik uzaklık olarak belirlendi. Molar derinlik ölçümleri ise molar dişlerin santral fossaları arasındaki yatay çizgiye yine en ilerideki kesici dişlerin interproksimal dişeti seviyesi arasındaki dik uzaklık hesaplandı (Şekil 1). ${ }^{10,11}$

Maksilla için ayrıca alan hesaplanması tüm dişlerin mukogingival birleşim hattı ile distalde 1. molar dişlerin distal noktaları arasındaki alan için yapıldı (Şekil 2).

\section{İstatistiksel analiz}

Normallik varsayımının incelenmesinde Kolmogorov-Smirnov testi kullanıldı. Normallik varsayımı sağlandığı için tanımlayıcı istatistikler ortalama ve standart sapmalar şeklinde sunuldu. Bağımlı iki grubun karşılaştırılmasında eşleştirilmiş t-testi kullanıldı. Anlamlıık düzeyi için üst sınır 0.05 olarak alındı.

Çalışmanın örneklem büyüklüğü, G-Power programı (HHU, Düsseldorf, Almanya) kullanılarak belirlendi.
Herzog ve arkadaşlarının ${ }^{14}$ yaptıkları çalışmada, elde ettikleri tedavi başı ve sonu interkanin mesafe değişikliği ortalama maksillada $1.63 \mathrm{~mm}(0.94,2.32)$ sonucunun istatistiksel olarak anlamlı çıkması göz önüne alındığında \%95 güven ile 0.71 effect size ve 0.98 gerçekleşen power değeri sağlanması için örneklem büyüklüğü 42 kişi olarak belirlendi. Çalışmamızda örneklem büyüklüğü 46 olarak arttırıldı.

\section{BULGULAR}

Maksillada inter-kanin, inter-1. premolar, inter-2. premolar ve inter-molar mesafelerde tedavi başı ve sonu değerler arasında anlamlı artış görüldü. Maksillada kanin derinliği tedavi sonunda tedavi başına göre anlamlı bir farklılık göstermezken, molar derinlikte tedavi sonunda anlamlı artış olduğu görüldü. Maksilla alan ölçümleri tedavi sonunda tedavi başına göre anlamlı artış gösterdi (Tablo 1).

Mandibulaya ait ölçümlerde ise interkanin mesafede tedavi sonunda tedavi başına göre anlamlı bir değişiklik olmadığı izlenirken, inter-1. premolar, inter-2. premolar, inter-molar, kanin derinliği ve molar derinliği ölçümlerinde tedavi sonunda anlamlı artış olduğu izlendi (Tablo 2).

Tablo 1. Maksillaya ait ölçümler

\begin{tabular}{|c|c|c|c|c|c|c|}
\hline \multirow{2}{*}{ Parametre } & \multicolumn{2}{|c|}{ TO } & \multicolumn{2}{|c|}{$\mathrm{T} 1$} & \multirow{2}{*}{$\begin{array}{c}\text { T1-T0 } \\
\text { Ort } \pm S S\end{array}$} & \multirow{2}{*}{$\frac{\text { Paired samples test }}{p}$} \\
\hline & Ort & SS & Ort & SS & & \\
\hline $13-23$ & 35.96 & 2.36 & 37.47 & 1.72 & $1.52 \pm 1.86$ & 0.000 \\
\hline $14-24$ & 43.59 & 2.29 & 46.19 & 1.68 & $2.60 \pm 1.61$ & 0.000 \\
\hline $15-25$ & 48.37 & 2.61 & 50.83 & 2.07 & $2.46 \pm 1.49$ & 0.000 \\
\hline $16-26$ & 53.47 & 2.70 & 54.41 & 2.41 & $0.93 \pm 1.39$ & 0.000 \\
\hline maksiller kanin derinlik & 6.65 & 1.48 & 6.87 & 0.89 & $0.25 \pm 1.44$ & 0.300 \\
\hline maksiller molar derinlik & 28.53 & 1.74 & 29.02 & 1.59 & $0.51 \pm 1.38$ & 0.020 \\
\hline maksiller alan & 902.37 & 84.18 & 984.06 & 75.96 & $81.69 \pm 54.79$ & 0.000 \\
\hline
\end{tabular}

Ort: Ortalama, SS: standart sapma, T0: tedavi başı, T1: tedavi sonu 
Tablo 2. Mandibulaya ait ölçümler

\begin{tabular}{|c|c|c|c|c|c|c|}
\hline \multirow{2}{*}{ Parametre } & \multicolumn{2}{|c|}{ TO } & \multicolumn{2}{|c|}{ T1 } & \multirow{2}{*}{$\frac{\text { T1-T0 }}{\text { Ort } \pm S S}$} & \multirow{2}{*}{$\frac{\text { Paired samples test }}{\mathrm{p}}$} \\
\hline & Ort & SS & Ort & SS & & \\
\hline $33-43$ & 29.12 & 1.76 & 29.08 & 1.47 & $-0.05 \pm 1.55$ & 0.845 \\
\hline $34-44$ & 38.23 & 1.85 & 39.41 & 1.49 & $1.18 \pm 1.41$ & 0.000 \\
\hline $35-45$ & 43.54 & 2.26 & 45.99 & 1.76 & $2.45 \pm 1.64$ & 0.000 \\
\hline $36-46$ & 48.93 & 2.61 & 49.84 & 2.15 & $0.91 \pm 1.50$ & 0.000 \\
\hline mandibular kanin derinlik & 4.77 & 1.63 & 5.19 & 1.16 & $0.42 \pm 1.09$ & 0.013 \\
\hline mandibular molar derinlik & 24.30 & 1.74 & 24.78 & 1.56 & $0.49 \pm 1.21$ & 0.009 \\
\hline
\end{tabular}

Ort: Ortalama, SS: standart sapma, T0: tedavi başı, T1: tedavi sonu

\section{TARTISSMA}

Günümüzde preform Ni-Ti alaşımlı ark telleri seviyeleme aşamasında birçok ortodontist tarafından sıklıkla tercih edilmektedir. Daha önceki yıllarda preform ark tellerinin dental arklar üzerindeki etkilerini inceleyen birçok araştırma yapılmıştır. Ancak bu çalışmalarda dental arklarda meydana gelen değişiklikler genellikle dental alçı modellerin fotokopileri üzerinde dişlerin iz düşümleri arası mesafelerin ölçülmesi veya kumpaslar yardımıyla alçı modeller üzerinde direkt mesafelerin ölçülmesi şeklindedir. Bu tarz ölçümler ile dental arkta meydana gelen değişimlerin detaylı ve doğru olarak tespit edilmesinde zorlukların olabileceği düşünülerek bu 3D çalışma planlanmıştır. Üç-boyutlu model analizleri ile dişler üzerindeki istenilen noktalar arası mesafeler kolaylıkla ölçülebilmektedir. Modellerin görüntüleri üzerinde yapılan büyütmeler ve modellerin her açıdan izlenebilmesi, referans noktalarının daha doğru bir şekilde belirlenmesine olanak sağlamaktadır. Sousa ve ark. ${ }^{16}$ üç boyutlu olarak yapılan ark genişliği ve uzunluğu ölçümlerinin dental modeller üzerinde dijital kumpas kullanılarak yapılan direkt ölçümler ile benzer olduğunu çalışmalarında göstermişlerdir. Verma ve ark. ${ }^{17}$ ise lineer ölçümlerde dijital ve konvansiyonel ölçümler arasında anlamlı farklılık olduğunu ancak bu sapmanın ortodonti alanında dijital model kullanımında sorun yaratacak büyüklükte olmadığını belirtmişlerdir.

Herzog ve ark. ${ }^{14}$ yaptıkları 3D analizde genişleme miktarlarını ölçmek için dişlerin tüberkül tepelerini kullanmışlardır. Çalışmamızda ise 3D analizin bir avantajı olarak dişlerin vestibül yüzeylerinde braket konumlarının orta noktalarına göre dişler arası mesafeler ölçülmüştür. Bu referans noktalarının seçilmesi ile dental arkta meydana gelen genişleme miktarlarının dişlerin tork hareketlerinden etkilenmeden daha gerçekçi olarak değerlendirileceği düşünülmüş ve amaçlanmıştır.

Bazı araştırmacılar, transversal genişlemeden kaçınmak amacı ile bireylerin ideal ark formlarının alçı dental modeller üzerinde belirlenmesi gerektiğine inanmaktadırlar. ${ }^{18,19}$ Ancak alçı model elde edilmesi hem vakit alıcı hem de depolanması ve korunması konusunda sıkıntıların olduğu bir uygulama olarak görülmektedir. Bu nedenle pratik ve daha ulaşılabilir olmaları nedeniyle prototip referans ark formlarının kullanımı birçok ortodontist tarafından tercih edilmektedir. ${ }^{8,20}$ Çalışmamıza dahil edilen bireylerde Ni-Ti ark formlarının seçiminde bireylerin tedavi başı ark formuna en yakın prototip ark formu seçilerek seviyeleme aşamalarında bu prototip ark formundaki ortodontik teller kullanılması kriterine uygunluk klinik kayıt formlarından tespit edilerek seçilmiştir.

Sabit ortodontik tedaviler sonrası üst kanin, 1. premolar, 2. premolar ve molar dişler arası mesafelerde artışlar daha önce yapılan çalışmalarda da gösterilmiştir. Braun ve ark. ${ }^{5}$ popüler kullanımda olan 33 farklı preform nikel titanyum ark tellinin doğal ark formuna uygunluğunu inceledikleri araştırmalarında hazır ark tellerinin doğal ark formundan farklılıklarını göstermişlerdir. Araştırıcılar, preform ark tellerinde kanin dişler arası mesafelerin doğal ark formuna göre maksillada ortalama $5.95 \mathrm{~mm}$, mandibulada ise $8.23 \mathrm{~mm}$ daha geniş iken 1. molar bölgesinde maksillada $0.84 \mathrm{~mm}$, mandibulada ise $2.68 \mathrm{~mm}$ daha fazla olduğunu belirlemişlerdir. Araştırıcılar ayrıca bukkal tüberkül tepelerinden yaptıkları ölçümler sonucu izlenen genişleme miktarlarının tedavi sonrası stabilitenin korunmasını etkileyebileceği ve ark derinliğinin azalmasına neden olarak dudak ve yüz estetiğini etkileyebileceği gibi iki önemli etkisinin izlenebileceğini bildirmişlerdir. ${ }^{5}$

Çalışmamızda izlenen genişleme miktarları, Braun ve arkadaşlarının ${ }^{5}$ sonuçlarına göre çok daha düşük miktarlarda bulunmuştur. Özellikle mandibulada kaninler arası mesafede anlamlı bir genişleme izlenmemesi önceki çalışmaların bulgularıyla farklılık göstermektedir. Bu farklılığın temel nedeni dişler arası mesafelerde diğer çalışmalarda tüberkül tepesi mesafeler kullanılırken, çalışmamızda braket konumlarının orta noktası belirlenerek dişler arası ölçümlerin yapılması olabilir. Bukkal tüberkül tepelerinin braketlerin tork değerlerine göre daha fazla konum değişikliği göstermesi beklenen bir sonuçtur. Çalışmamızda dişler arası mesafeleri ölçmek için kullandığımız referans noktaları ise tork değişimlerinden tüberkül tepelerine göre daha az etkilenecek noktalar olarak düşünülmüş ve çalışmamızda bu nedenle tercih edilmişlerdir.

Herzog ve ark. ${ }^{14}$ ise çekimsiz tedavi ettikleri hastaların inter-kanin ve inter-molar mesafelerini 3D model analizi ile değerlendirdikleri çalışmalarında, Braun ve ark. ${ }^{5}$ ile benzer olarak bukkal tüberkül tepelerini referans noktaları olarak kullanmışlardır. Maksillada kanin dişler arası mesafede $1.63 \mathrm{~mm}$, mandibulada ise 1.20 $\mathrm{mm}$ artış bildirmişlerdir. İnter-molar mesafelerde ise 
maksillada $1.57 \mathrm{~mm}$, mandibulada ise $1.27 \mathrm{~mm}$ artış bulmuşlardır.

Çalışmamızda inter-kanin ve inter-molar mesafelerde elde ettiğimiz genişleme miktarları, Herzog ve ark. ${ }^{14}$ çalışması ile oldukça benzer sonuçlar göstermektedir. Araştırmacılar 3D ölçümler yaptıkları araştırmalarında çalışmamızdan farklı olarak referans noktalarını bukkal tüberkül tepesi olarak seçmişlerdir. İki çalışma arasındaki en büyük farklılık, mandibular interkanin mesafelerde ortaya çıkmaktadır. Çalışmamızda mandibulada interkanin mesafede anlamlı bir artış izlenmemiş ancak 1. premolar dişler arası mesafede anlamlı artış görülmüştür. Herzog ve arkadaşlarının ${ }^{14}$ tespit ettiği mandibular kanin dişler arası genişleme miktarı, çalışmamızdaki 1. premolar dişler arası genişleme miktarı ile benzerdir. Ancak araştırmacılar 1. premolar dişler arası mesafe ile ilgili herhangi bir ölçüm yapmamışlardır.

Kim ve ark. ${ }^{15}$ çekimsiz tedavi ettikleri hastalarda maksiller ve mandibular inter-kanin mesafelerde tedavi başı ve sonu değerlerdeki değişimlerin minimal seviyede olduğunu ve istatistiksel olarak anlamlı olmadıklarını bildirmişlerdir. Araştırmacılar, alçı dental modeller üzerinde bukkal tüberkül tepelerini referans alarak yaptıkları ölçümlerde 1. premolar dişler arasında genişleme miktarlarının maksillada ortalama $1.9 \mathrm{~mm}$ iken mandibulada $1.31 \mathrm{~mm}$ olduğunu belirtmişlerdir. Bu sonuçlar, çalışmamızda 1. premolar dişler arasındaki genişleme değerlerine yakın sonuçlardır (maksillada $1.9 \mathrm{~mm}$, mandibulada $1.18 \mathrm{~mm}$ ).

Ortodontik tedavilerin en önemli amaçlarından biri elde edilen tedavi sonuçlarının korunmasıdır. Daha önceki çalışmalar dişlerin tedavilerden sonra orijinal pozisyonlarına dönme eğilimi gösterdikleri yönünde raporlar sunmuştur. ${ }^{21,22}$ Akyalçın ve ark. ${ }^{13}$ maksillada 3D model analizi ile yaptıkları çalışmalarında rugae pozisyonlarını dikkate alarak ön, orta ve arka bölge dental ark genişliklerini ölçmüştür. Araştırmacılar çekimsiz vakalarda tedavi sonunda her üç bölge ölçümlerinde de artışlar olduğunu, ortalama 3 yıllık retansiyon dönemi sonunda ise arka ark genişliğinde anlamlı bir azalma olduğunu bildirmişlerdir.

Boley ve ark. ${ }^{21}$ alt ve üst çenede 1. premolar çekimli sabit ortodontik tedavi yaptıkları hastalarında tedavi sonunda mandibulada interkanin mesafede 1.7 $\mathrm{mm}$ artış olduğunu ancak retansiyon döneminde 1.4 mm'lik daralma izlendiğini bildirmişlerdir. Ancak 5 yıllık postretansiyon döneminde takip ettikleri 106 hastanın \%80.5'inde 3.5 mm'den daha az, \%19.5'inde ise 3.5$6.5 \mathrm{~mm}$ çapraşıklık izlendiğini bildirmişlerdir. Araştırmacılar, maksillada inter-kanin mesafede tedavi sürecinde $1 \mathrm{~mm}$ genişleme izlemiş ve post-retansiyon döneminde anlamlı bir değişiklik tespit etmemişlerdir.

Çalışmamızda mandibular kanin dişler arası mesafede artış olmaması nüks açısından olumlu bir durum olarak değerlendirilebilir. Ancak 1. premolar dişler arası mesafede artış olması, post-retansiyon döneminde izlenebilecek muhtemel bozulmalar açısından göz ardı edilmemelidir. Çalışmamızda mandibular kanin diş- ler arasında genişleme izlenmemesinin nedeni olarak seçilen preform ark tellerinin hastaların tedavi başı ark formları ile uyumlu olmaları düşünülebilir. Ancak bu arklar ile 1. premolar, 2. premolar ve 1. molar dişler arasında genişleme izlendiği de unutulmamalıdır.

Benkli ve ark. ${ }^{23}$ mandibular ön bölgede orta derecede çapraşıklığı bulunan bireylerde Ni-Ti arklar ile 16 haftalık seviyeleme sonrasında hem kanin derinlik ölçümlerinde hemde molar derinlik ölçümlerinde anlamlı artış olduğunu bildirmişlerdir. Kanin derinliğinde artış seviyeleme sonrasında ortalama $0.5 \mathrm{~mm}$ iken molar derinlikte artış ortalama $1.5 \mathrm{~mm}$ olarak belirlenmiştir. Kanin derinlik artışı çalışmamızda mandibula için Benkli ve ark. ${ }^{23}$ sonuçları ile benzer iken molar derinlik artışı çalışmamızda daha az olarak tespit edilmiştir. Bu farklılık Benkli ve arkadaşlarının ${ }^{23}$ kullandıkları braket sistemlerinin çalışmamızda kullanılan konvansiyonel braketlerden farklı olması ve orta seviye çapraşıklığa sahip bireylerin tedavi edilmiş olmalarıyla alakalı olarak oluştuğunu düşünmekteyiz.

Günümüzde 3D model analizleri ile alan hesaplanması artık mümkün hale gelmiştir. ${ }^{24-26}$ Birçok araştırmada kullanılan alçı modeller üzerinde mesafe ölçümleri yapılabilmesine rağmen alan hesaplamaları yapılamamaktadır. Bizzaro ve ark. ${ }^{27}$ bukkalde konumlanmış kanin dişlerin mevcudiyetinde palatal morfolojide ne gibi farklılıklar olduğunu palatal alan ve hacim ölçümleri ile değerlendirmişlerdir. Üç-boyutlu olarak yaptıkları çalışmalarında taradıkları alçı modeller üzerinde çalışmamızdakinden farklı bir program kullanmışlardır. Çalışmamızda maksiller dişlerde izlenen genişleme ile birlikte palatinal bölgede ne gibi bir değişim olduğu alan hesaplaması ile belirlenmeye çalışılmıştır. Ancak elde edilen sonuçların karşılaştırılarak tartışılması için benzer çalışmalara ulaşılamamıştır. Sonuçlarımız minimal çapraşıklık vakalarında preform arklarla maksillada kanin, 1. premolar, 2. premolar ve 1. molar dişlerde anlamlı genişleme miktarlarıyla birlikte palatinal bölgede anlamlı bir yüzey alan artışı olduğunu göstermektedir.

Diğer taraftan, anterior dental arkta çapraşıklık miktarı arttıkça posterior bölge üzerindeki ekspansif etkinin preform arktaki esnemeye bağlı olarak artabileceğini düşünmekteyiz. Bu nedenle orta düzeydeki çapraşıklık vakaları üzerinde oluşan etkilerin ayrıca değerlendirilmesi yararlı olacaktır.

\section{SonUÇ}

Basit seviyeleme vakalarında düz tel tekniği ile birlikte kullanılan preform arkların hem maksiller hem de mandibular dental arklarda anlamlı transversal boyut ve alan artışı yarattığı görülmüştür. 


\section{KAYNAKLAR}

1. Ricketts RM. A detailed consideration of the line of occlusion. Angle Orthod 1978;48:274-82

2. Felton JM, Sinclair PM, Jones DL, Alexander RG. A computerized analysis of the shape and stability of mandibular arch form. Am J Orthod Dentofacial Orthop 1987;92:478-83.

3. Raberin M, Laumon B, Martin JL, Brunner F. Dimensions and form of dental arches in subjects with normal occlusions. Am J Orthod Dentofacial Orthop 1993;104:67-72.

4. Knoot B. Longitudinal study of dental arch widths at four stage of dentition. Angle orthod 1972;42:387-94

5. Braun S, Hnat WP, Leschinsky R, Legan HL. An evaluation of the shape of some popular nickel titanium alloy preformed arch wires. Am J Orthod Dentofacial Orthop 1999;116:1-12.

6. Oda S, Arai K, Nakahara R. Commercially available archwire forms compared with normal dental arch forms in a Japanese population. Am J Orthod Dentofacial Orthop 2010;137:520-7.

7. Braun S, Hnat WP, Fender DE, Legan HL. The form of the human dental arch. Angle Orthod 1998;68:29-36.

8. Triviño T, Siqueira DF, Scanavini MA. A new concept of mandibular dental arch forms with normal occlusion. Am J Orthod Dentofacial Orthop 2008;133:15-22.

9. Germec-Cakan D, Taner TU, Akan S. Arch-width and perimeter changes in patients with borderline Class I malocclusion treated with extractions or without extractions with air-rotor stripping. Am J Orthod Dentofacial Orthop 2010;137:731-7

10. Cho MY, Choi JH, Lee SP, Baek SH. Three-dimensional analysis of the tooth movement and arch dimension changes in Class malocclusions treated with first premolar extractions: a guideline for virtual treatment planning. Am J Orthod Dentofacial Orthop 2010;138:747-57

11. Kook YA, Nojima $K$, Moon HB, McLaughlin RP, Sinclair PM. Comparison of arch forms between Korean and North American white populations. Am J Orthod Dentofacial Orthop 2004;126:680-6.

12. Kim KY, Bayome M, Kim K, Han SH, Kim Y, Baek SH, et al. Threedimensional evaluation of the relationship between dental and basal arch forms in normal occlusion. Korean J Orthod 2011;41: 288-96.

13. Akyalcin S, Erdinc AE, Dincer B, Nanda RS. Do long-term changes in relative maxillary arch width affect buccal-corridor ratios in extraction and nonextraction treatment? Am J Orthod Dentofacial Orthop 2011;139:356-61

14. Herzog C, Konstantonis D, Konstantoni N, Eliades T. Archwidth changes in extraction vs nonextraction treatments in matched Class I borderline malocclusions. Am J Orthod Dentofacial Orthop 2017; 151:735-43

15. Kim E, Gianelly AA. Extraction vs nonextraction: arch widths and smile esthetics. Angle Orthod 2003;73:354-8.

16. Sousa MV, Vasconcelos EC, Janson G, Garib D, Pinzan A. Accuracy and reproducibility of 3-dimensional digital model measurements. Am J Orthod Dentofacial Orthop 2012;142:269-73.

17. Verma RK, Singh SP, Verma S, Kumar V, Bhupali NR, Arora S. Comparison of reliability, validity, and accuracy of linear measurements made on pre-and posttreatment digital study models with conventional plaster study models. J Orthodont Sci 2019;8:18.

18. Andrews LF, Andrews WA. The syllabus of the Andrews orthodontic philosophy. 9th ed. San Diego, CA: L.F. Andrews Foundation; 2001.

19. Strang RHW. Factors associated with successful orthodontic treatment. Am J Orthod 1952:38;790-800.

20. Interlandi S. New method for establishing arch form. J Clin Orthod 1978;12:843-5

21. Boley JC, Mark JA, Sachdeva RC, Buschang PH. Long-term stability of Class I premolar extraction treatment. Am J Orthod Dentofacial Orthop 2003;124:277-87.

22. de la Cruz A, Sampson P, Little RM, Artun J, Shapiro PA. Long-term changes in arch form after orthodontic treatment and retention. Am J Orthod Dentofacial Orthop 1995;107:518-30.

23. Benkli YA, Büyük SK, Koşgin $S$. Alt çene ön bölge çapraşıklığa sahip olgularda iki farklı braket sisteminin kısa dönem etkilerinin değerlendirilmesi. Yeditepe J Dent 2019;15(2):152-8.

24. Generali C, Primozic J, Richmond S, Bizzarro M, Flores-Mir C, Ovsenik M, et al. Three-dimensional evaluation of the maxillary arch and palate in unilateral cleft lip and palate subjects using digital dental casts. Eur J Orthod 2017;39:641-5.

25. Primožič J, Perinetti G, Richmond S, Ovsenik M. Three-dimensional longitudinal evaluation of palatal vault changes in growing subjects. Angle Orthod 2012;82:632-6.

26. Primožič J, Perinetti G, Contardo L, Ovsenik M. Diagnostic performance of 3 -dimensional evaluation of palatal vault changes in assessing successful treatment of constricted maxilla in growing subjects. Am J Orthod Dentofacial Orthop 2013;143:42-9.

27. Bizzarro M, Generali C, Maietta S, Martorelli M, Ferrillo M, FloresMir C, et al. Association between 3D palatal morphology and upper arch dimensions in buccally displaced maxillary canines early in mixed dentition. Eur J Orthod 2018;40:592-6.

\section{Evaluation of the effects of preform arch wires on dental arch by 3D model analysis}

\section{Abstract}

OвJEctive: The aim of this study was to evaluate the effects of preform arch wires used in fixed orthodontic treatments on the lower and upper dental arch-forms with three-dimensional (3D) model analysis.

Materials and Method: This study consisted of pre-treatment (T0) and post-treatment (T1) dental models of 46 patients who had minimal anterior crowding (approximately $3 \mathrm{~mm}$ ) on the lower and upper arch, and treated in Gazi University, Faculty of Dentistry, Department of Orthodontics. Dental models were scanned using 3Shape R700 3D Scanner and the data was imported into the 3Shape ortho analyzer software program in the form of STL image files. Upper and lower inter-canine, inter-1. bicuspid, inter-2. bicuspid, inter-molar distances, canine and molar depth measurements were performed. Calculation of the area for maxilla was measured between the mucogingival junction of all teeth and the distal points of the 1st molar teeth. Kolmogorov-Smirnov test was used to check the normality. Descriptive statistics were presented as means and standard deviations. Paired t-test was used to compare two dependent groups. The level of significance was taken as $\mathbf{0 . 0 5}$

RESULTS: Significant increases were observed in all parameters except canine depth in the maxilla and inter-canine width during treatment. The highest increase in the maxilla was observed in the inter-1. bicuspid with a value of $2.6 \mathrm{~mm}(p<0.001)$. On the other hand, the highest increase in the mandible was observed in the inter-2. bicuspid dimension with a value of $2.45 \mathrm{~mm}(p<0.001)$. The increase in maxillary area was significant with an average of $\mathbf{8 1 . 6 9}$ $\mathrm{mm} 2(p<0.001)$. The increase in molar depth was determined as $0.5 \mathrm{~mm}$ for both maxilla and mandible $(p<0.001)$.

CONCLUSION: Ni-Ti leveling arches, which are selected in accordance with the pre-treatment arch form of the patients, cause significant increases in the transversal direction in both the maxilla and mandible.

KEYWORDS: Orthodontics; orthodontic wires; imaging, three-dimensional 